CASE REPORT

\title{
The use of interferon beta in relapsing-remitting multiple sclerosis
}

\author{
L J Etheridge, D W Beverley, C Ferrie, E McManus
}

Arch Dis Child 2004;89:789-791. doi: 10.1136/adc.2003.040881

The use of interferon beta-la to treat multiple sclerosis in a child of 7 years of age is discussed. To date, there is only one other published report of the use of interferon beta in a child as young as this. One year after commencing treatment she had shown significant clinical improvement, with a marked reduction in number of relapses. In her second year of treatment she suffered a major relapse from which she slowly recovered.

M ultiple sclerosis (MS) is a chronic inflammatory disease of the central nervous system with a clinical onset usually occurring between the ages of 20 and 40. Onset below the age of 10 is rare, reported in less than $1 \%$ of cases. ${ }^{1}$ The majority of children with MS exhibit a relapsing-remitting course and the frequency of relapses is thought to correlate with eventual disability.

There has been much interest in the role of interferon beta to reduce disease activity in adults with MS over the past decade, with trials showing clinical and magnetic resonance imaging (MRI) improvement, reduction in relapse frequency and severity, and improvement in disability scores. ${ }^{2-4} \mathrm{~A}$ systematic review of its role in relapsing-remitting MS showed that the number of patients who experienced exacerbations was reduced by about $25 \%$ during the first year of treatment. However, over a longer period results were inconclusive, largely due to insufficient data. ${ }^{5}$

There is far less published data available on the use of interferon beta in children. One case is reported from North America of the use of interferon beta in a child aged 7 years. This child commenced treatment with interferon beta-1b four years after a diagnosis of relapsing-remitting MS was made. There was marked clinical improvement during the first year of treatment but he subsequently developed neutralising antibodies, corresponding with new lesions on cranial MRI but little clinical change. After three years of treatment, the authors report there have been no side effects and no significant relapses. ${ }^{6}$

\section{CASE REPORT}

A $4 \frac{1}{2}$ year old girl presented with a 24 hour history of nonspecific headaches, slurred speech, and left sided weakness of the arm and face. Cranial computed tomography (CT) showed 4-5 multifocal enhancing mass lesions. She had a mild neutrophilia but examination of the cerebrospinal fluid (CSF) was normal. All samples sent for serology proved negative. A diagnosis of para-infectious encephalitis was made and she was treated for 10 days of intravenous antibiotics and acyclovir. Five days of dexamethasone was given with resultant clinical and CT improvement.

She was readmitted two weeks later with pain and weakness in her right leg and arm and a prolonged right sided motor seizure. T2 weighted MRI at this time showed abnormal signal in the white matter in both fronto-parietal regions, extending to the Sylvian fissure, with some cystic necrosis on the left (fig 1). Tl weighted images following contrast showed new ring-like enhancements of the right frontal lobe and thalamus. MRI spine was normal. A brain biopsy was performed which showed a necrotising demyelinating lesion. Ophthalmological examination revealed slight temporal pallor of the optic discs but was otherwise normal. Serological tests were negative for toxoplasmosis, herpes simplex, and Whipple's bacillus. She improved with steroids and carbamazepine. The likely diagnosis was now believed to be acute multiple sclerosis.

Six weeks later, she was readmitted with bilateral visual loss. A repeat MRI revealed a new area of abnormal enhancement on the left side of the optic chiasm. Treatment with intravenous methylprednisolone for three days led to some improvement in vision and prednisolone $2 \mathrm{mg} / \mathrm{kg} /$ day was started. She then had a further relapse, characterised by unsteady gait, increasing visual difficulties, an expressive dysphasia, and a change in personality. A CSF sample sent at this time showed oligoclonal bands. This episode was again treated with steroids, which were reduced after six weeks and stopped by three months. When seen at this time, she had pyramidal signs in all her limbs, especially on the right, and a broad based gait.

Over the second and third years of her illness, she suffered increasing numbers of relapses consistent with episodes of acute demyelination, an average of $8-10$ per year. These were treated with intravenous methylprednisolone and prolonged courses of oral corticosteroids. However, she failed to make a full recovery from these episodes and had increasing cognitive and language difficulties, decreasing vision in the right eye, loss of bladder control, and required a wheelchair most of the time. Neurological examination was consistently abnormal, with increased tone, reduced power, and brisk reflexes in the lower limbs, up-going plantar responses, and a stiff legged, unsteady gait. She suffered increasing numbers of focal and tonic-clonic seizures. Repeated investigations showed normal haematology, biochemistry, inflammatory markers, autoantibodies, serology, plasma and CSF lactate, and angiotensin converting enzyme. CSF had normal protein, cells, and glucose on all occasions with no organisms identified. Treatment with intravenous immunoglobulin and cyclosporin was tried with little effect, and she continued to need high doses of steroids and frequent admissions for intravenous methylprednisolone. She developed raised blood pressure and hirsutism.

The decision was made to start interferon beta in February 2002, when she was 7 years old. Interferon beta-la (Rebif, Serono) was started at a dose of 2 MIU subcutaneously three times a week, the equivalent of a third of the standard adult dose. On the day of her first injection, she suffered a relapse with the development of a bulbar palsy. She was therefore given intravenous methylprednisolone for five days. The next few injections were tolerated well and the dose of oral 


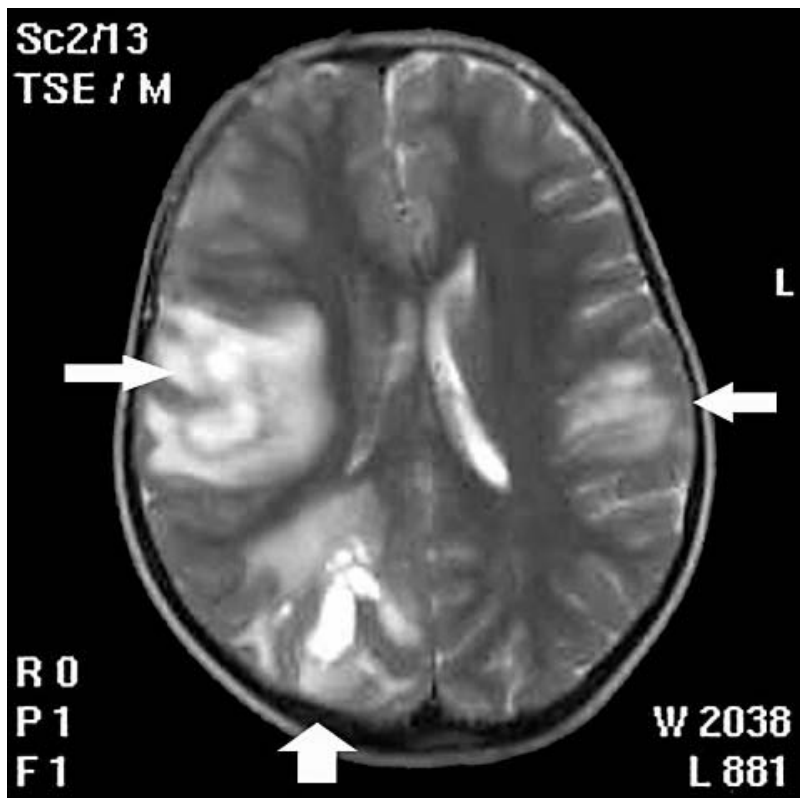

Figure 1 T2 weighted MRI showing abnormal signal in the white matter in both fronto-parietal regions, extending to the Sylvian fissure, with some cystic necrosis on the left.

steroids weaned. After one month, both the dysphagia and her mobility were improving. She had not experienced any side effects of the interferon and had normal haematology, electrolytes, and liver function on monitoring. At three months, she was able to walk 20 yards with support. Her parents reported a slight deterioration in her ability to walk on the days she received her injection of interferon, but this was transient. After one year of treatment she had experienced three minor relapses, associated with intercurrent viral illnesses. This is less than half the annual number experienced previously. The dose of interferon was increased to 3 MIU and tolerated well.

During the second year of her treatment, she suffered a further episode of demyelination involving the brain stem and pons, which did not respond to seven days of intravenous methylprednisolone. Her interferon beta dose was increased to $6 \mathrm{MIU}$, full adult dose, and she slowly improved over a period of months.

\section{DISCUSSION}

In 1979, Poser published diagnostic criteria for adults with MS. ${ }^{7}$ However, there are no specific guidelines for children. MS developing under the age of 6 years is reported to be characterised by more frequent relapses than in adults, and the earlier the age of onset, the worse the prognosis. The frequency of cerebellar involvement and seizures appears to be higher than in the adult population. Children appear to have greater systemic upset at presentation but recovery is quicker. An alternative diagnosis is more likely to be suggested after initial presentation. Most have their second exacerbation within one year. ${ }^{8}$ Our patient had clinical MS using Poser's guidelines.

There have been no published controlled trials looking at the treatment of MS in children. The treatment of choice has been steroids, although other medications have been tried, including intravenous immunoglobulin, cyclophosphamide, cyclosporine, or azathioprine. ${ }^{9}$ In January 2002 a National Institute for Clinical Excellence report into the use of interferon beta in MS concluded that there was not enough evidence of clinical effectiveness to justify its considerable expense, currently $£ 7000-10000$ per patient per year. ${ }^{10}$ There is far less published data on the use of interferon beta in children. There are two other published articles looking at interferon beta treatment in a total of 17 children, aged between 7 and 17 years, with relapsing-remitting MS. These report use of a variety of brands of interferon with doses ranging from half to full adult dose (table 1).

Waubant et al investigated the tolerability of interferon beta in nine children between the ages of 8 and 15 years. No child discontinued treatment because of an adverse effect. The commonest reported side effects were myalgia and flulike symptoms. ${ }^{11}$ There is no other report of transient deterioration in function on the day of the injection, as experienced by our patient.

The decision to commence interferon beta treatment in our patient was discussed over a long period, amid a time of controversy and speculation surrounding its provision within the National Health Service The use of interferon beta in children is limited by a lack of data on safety, efficacy, dosage, and optimum timing. It was eventually started when the frequency and severity of relapses, as well as the side effects of alternative treatments, were limiting her quality of life. In the first year of treatment, she showed a significant clinical improvement with less than half the number of relapses previously experienced. Despite a later significant

Table 1 Reported uses of interferon beta in children ${ }^{69}$

\begin{tabular}{|c|c|c|c|c|c|c|}
\hline Gender & $\begin{array}{l}\text { Age at onset } \\
\text { of MS (y) }\end{array}$ & $\begin{array}{l}\text { Age at start of } \\
\text { treatment }(y)\end{array}$ & $\begin{array}{l}\text { IFN used } \\
\text { and dose }\end{array}$ & $\begin{array}{l}\text { IFN continued } \\
\text { or stopped }\end{array}$ & $\begin{array}{l}\text { Number relapses } \\
\text { before }\end{array}$ & $\begin{array}{l}\text { Number relapses } \\
\text { during }\end{array}$ \\
\hline$M$ & 3.0 & 7.0 & $1 \mathrm{~b}: 4 \mathrm{MIU}$ & Continued & 5 & 0 \\
\hline$M$ & 8.5 & 10.5 & 1a: 3 MIU & Continued & 3 & 0 \\
\hline $\mathrm{F}$ & 11.0 & 15.0 & $?: A D$ & Continued & 3 & 0 \\
\hline$M$ & 12.0 & 15.5 & $?: A D$ & Continued & 3 & 1 \\
\hline $\mathrm{F}$ & 12.0 & 14.5 & $?: A D$ & Continued & 6 & 1 \\
\hline $\mathrm{F}$ & 12.0 & 16.0 & $?: A D$ & Stopped & 7 & 5 \\
\hline $\mathrm{F}$ & 12.0 & 17.0 & $?: A D$ & Continued & 6 & 0 \\
\hline$F$ & 12.5 & 15.5 & ?: AD & Stopped & 10 & 3 \\
\hline $\mathrm{F}$ & 13.0 & 14.0 & $?: A D$ & Continued & 5 & 5 \\
\hline $\mathrm{F}$ & 13.0 & 16.0 & $?: A D$ & Continued & 10 & 5 \\
\hline $\mathrm{F}$ & 14.0 & 16.0 & $?: A D$ & Continued & 3 & 1 \\
\hline $\mathrm{F}$ & 14.0 & 15.0 & $?: A D$ & Continued & 4 & 1 \\
\hline $\mathrm{F}$ & 14.0 & 15.0 & $?: A D$ & Stopped & 2 & 3 \\
\hline $\mathrm{F}$ & 14.5 & 15.5 & $?: A D$ & Continued & 2 & 4 \\
\hline $\mathrm{F}$ & 15.0 & 16.0 & $?: A D$ & Stopped & 3 & 5 \\
\hline $\mathrm{F}$ & 15.5 & 17.0 & $?: A D$ & Continued & 3 & 0 \\
\hline $\mathrm{F}$ & 15.5 & 17.0 & $?: A D$ & Continued & 3 & 1 \\
\hline
\end{tabular}

IFN, interferon; $A D$, adult dose of interferon used. 
relapse she continues to regain function and enjoy a much improved quality of life.

\section{Authors' affiliations}

L J Etheridge, Bradford Royal Infirmary, UK

D W Beverley, E McManus, York Hospital, UK

C Ferrie, Leeds General Infirmary, UK

Correspondence to: Dr D W Beverley, Consultant Paediatrician, York Hospital, Wigginton Road, York YO31 8HE, UK;

David.W.Beverley@York.nhs.uk

Accepted 16 December 2003

\section{REFERENCES}

1 Boiko A, Vorobeychik G, Paty D, et al. Early onset multiple sclerosis. A longitudinal study. Neurology 2002:59:1006-10.

2 PRISMS Study Group. PRISMS-4: long term efficacy of interferon beta- la in relapsing MS. Neurology 2001;56:1628-36.
3 Fernandez O, Arbizu T, Izquierdo G, et al. Clinical benefits of interferon betala in relapsing-remitting MS: a phase IV study. Acta Neurol Scand 2003;107:7-11.

4 Paolillo A, Pozilli C, Giugni E, et al. A 6 year clinical and MRI follow-up study of patients with relapsing-remitting multiple sclerosis treated with interferonbeta. Eur J Neurol 2002;9:645-55.

5 Filippini G, Munari L, Incorvaia B, et al. Interferons in relapsing remitting multiple sclerosis: a systematic review. Lancet 2003:361:545-52.

6 Adams AB, Tyor WR, Holden KR. Interferon beta-1b and childhood multiple sclerosis. Paediatr Neurol 1999;21:481-3.

7 Poser S, Wilkstrom J, Baver HJ. Clinical data and identification of special forms of multiple sclerosis with a standardised documentation system. J Neurol Sci 1979;40:159-68

8 Ruggieri M, Polizzi A, Pavone L, et al. Multiple sclerosis in children under 6 years of age. Neurology 1999;53:478-84.

9 Mikaeloff $Y$, Moreau T, Debouverie M, et al. Interferon-beta treatment in patients with childhood-onset multiple sclerosis. J Pediatr 2001; 139:443-6.

10 National Institute for Clinical Excellence. Beta interferon and glatiramer acetate for the treatment of multiple sclerosis: technology appraisal number 32. Jan 2002. www.nice.org.uk.

11 Waubant E, Hietpas J, Stewart T, et al. Interferon beta-1 a in children with MS is well tolerated. Neuropediatrics 2001;32:211-13.

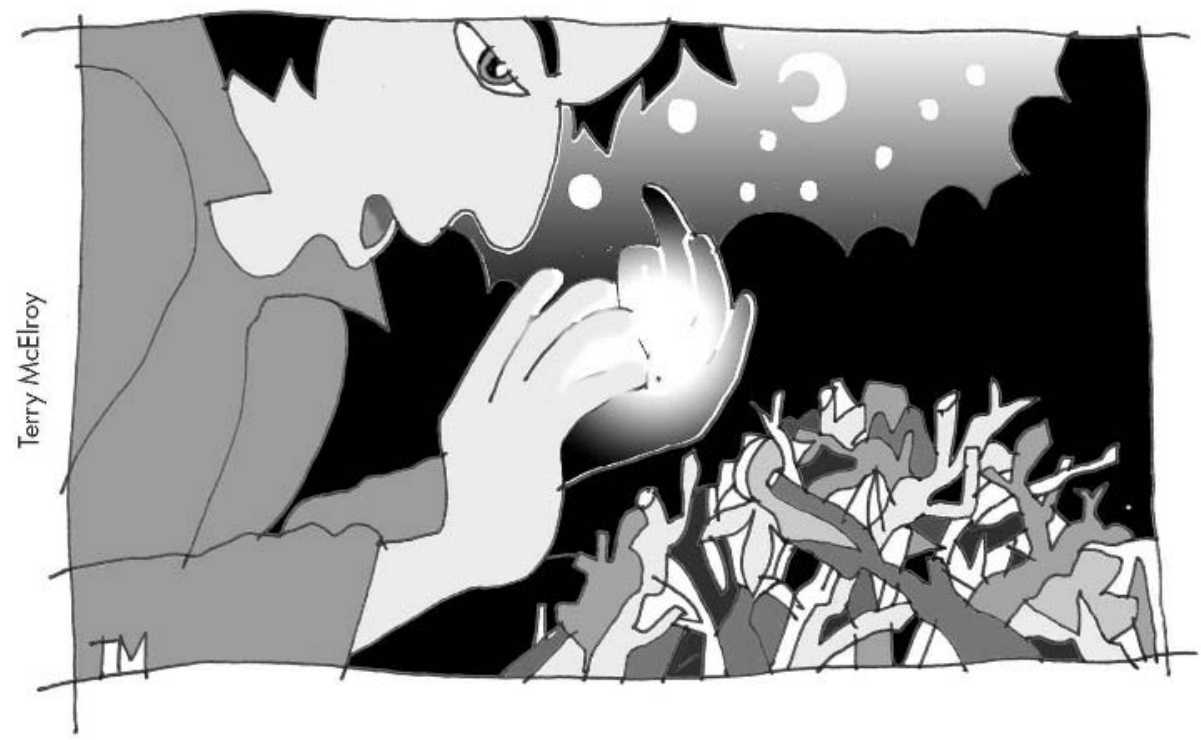

